\title{
Discusiones en torno a la esencia del vínculo jurídico laboral
}

\author{
Por Adolfo Nicolás Balbín*
}

Sumario: 1.- Introducción. 2.- El vínculo jurídico laboral como figura con fuerza de imperatividad legal. 3.-Algunas posturas relacionistas. Su faz clásica. 4.- Críticas formuladas a las tesis relacionistas. 5.- Algunas ideas contractualistas para delimitar la relación de apropiación laboral. 6.- Posturas intermedias. 7.- Nuestra posición: la relación de trabajo como relación de poder. 8.- Conclusiones. 9.- Bibliografía.

\section{1.- Introducción}

En el presente trabajo, nos proponemos analizar la esencia del vínculo jurídico laboral, alejándonos de la denominación quizá más utilizada para identificar el tracto apropiativo habido entre trabajador y empleador, en donde razones de índole económica superan a la definición jurídica positiva de esa figura del mundo del derecho, al reconocerse explícita e implícitamente más poderes al empleador, en comparación con el titular de la energía humana.

Para simplificar, diremos que la figura del "contrato" de trabajo es la que usualmente se utiliza para individualizar a la relación entre trabajador y empleador. De hecho, el cuerpo que sistematiza la rama del Derecho Individual del Trabajo (Ley 20.744/74), privilegia esa acepción, desbrozando sus elementos esenciales en su artículo 21.

Pero a su vez, el artículo 22 de la misma ley individualiza la denominada relación de trabajo, lo que más allá de los ensambles jurídicos que se pueden establecer entre ambas figuras, ha llevado a una rica discusión que exorbita la normativa positiva, y se adentra en la sustancia misma del tracto apropiativo laboral.

* Abogado (UNLP). Profesor Adjunto en Derecho Social. Facultad de Ciencias Jurídicas y Sociales, Universidad Nacional de La Plata, Argentina Correo electrónico: nicolasbalbin@hotmail.com 
Existen en doctrina como se sabe dos posturas diferentes en torno a la delimitación de la naturaleza jurídica del vínculo jurídico laboral, que son la tesis contractualista y la relacionista (también conocida como postura incorporacionista, y con una vertiente en el institucionalismo). Cada una de las cuales tiene adeptos y contradictores, tomando nosotros partido por una de ellas, aunque por una cuestión de claridad entendemos fructífero exponer los argumentos principales de ambas, sus críticas, las tesis intermedias, y finalmente la síntesis particular a que el tema seleccionado nos conduce.

Adelantamos que nosotros adherimos a la teoría relacionista (o al menos a una vertiente de ella), y creemos que desde ese panorama nuestra línea de investigación adquiere mayor justificación, prosiguiendo a continuación con el plan antes estipulado.

\section{2.- El vínculo jurídico laboral como figura con fuerza de imperatividad legal}

Nutrido de los principios fundamentales del derecho del trabajo, se entiende que media un vínculo jurídico laboral cuando una persona física -trabajador-, se compromete $\mathrm{u}$ obliga a prestar servicios en beneficio de otro sujeto -empleador (pudiendo ser este una persona física, o jurídica, o bien un conjunto de ambas, tal cual se entiende por la mayoría de la doctrina hoy en día)-, sometiéndose al mismo en base a una relación de dependencia, a cambio de una remuneración. En esa línea, es harto aceptado hoy día el carácter de imperatividad legal que hidrata tal figura jurídica desde que, advertidos aquellos elementos tipificantes, se entiende que ha sido celebrado un "contrato de trabajo", con los efectos que tal negocio supone, y más allá de cualquier denominación que las partes le hayan querido atribuir, otorgándose especial dinamismo al principio de primacía de la realidad, y a la prevalencia de la verdad objetiva ${ }^{1}$ (Etala, 2011:100). Tal es el criterio emanado del artículo 21 de la LCT.

De esta manera, dinamizando lo establecido por el artículo 1 inciso d) de la Ley 20.744, se entiende que la voluntad de las partes tiene el carácter de fuente

$1 \mathrm{Al}$ respecto, la CNAT ha dicho que: "La circunstancia de que se haya firmado un contrato en que se califica la prestación como locación de servicios o que la demandante percibiera una retribución bajo la denominación de honorarios, no reviste relevancia a los fines de la caracterización de la relación, pues debe prevalecer el contenido real de la vinculación, ya que el rigorismo de las formas cede para que prime la verdad objetiva y la naturaleza concreta de la relación existente" (Sala I, 31/5/99, DT, 1999-B-2276). 
del derecho del trabajo, al permitírseles dar origen a una norma de carácter individual y no estatal (o autoritario), productora de derechos y obligaciones entre los sujetos atravesados por ese haz obligacional, ello sin perjuicio de la limitación a la libre disponibilidad jurídica que matiza esa especial relación, sobre todo en punto a la libre disposición de hecho y de derecho -dentro de ese amalgama legal- por parte del trabajo.

Entonces, prefigurándose esa reducción en la voluntad del trabajador (aún cuando no sea total, pues dado ese caso se entraría en el campo de enlaces político-culturales superados al menos por nuestro marco socio-positivo contemporáneo, como la esclavitud), se intenta menguar la desigualdad negocial habida en el binomio trabajador-empleador, a partir de un conjunto de reglas y/o presunciones que, desde el orden público laboral ${ }^{2}$, tienden a materializar el rol científico primero del derecho del trabajo, proyectando su carácter tuitivo al particular enlace político que une a quienes detentan en la relación de trabajo, propiedades social y económicamente desiguales.

A través del orden público laboral, el derecho del trabajo fija normas mínimas de protección y regulación, irrenunciables para las partes, a partir de cuyas arenas básicas debe campear la voluntad de los sujetos obligados que, adelantamos, se vinculan en derredor de un vínculo de productor y reproductor de micro poderes con efecto expansivo que definen inevitablemente la naturaleza de esa especial figura de carácter eminentemente económico, que la Ley 20.744 titula como contrato de trabajo ${ }^{3}$.

Ahora bien, adentrándonos al núcleo de este trabajo, analizaremos las diferentes posturas que se han dado en doctrina, a fin de aproximarnos al verdadero significado del nexo existente entre trabajador y empleador.

2 En clarificadoras palabras, ha dicho Rodolfo Capón Filas que: "el orden público funciona como el principal concepto válvula en derecho laboral. Lleva al ordenamiento hacia los valores ideales de justicia social, solidaridad y cooperación; siendo abierto, permite recepcionar las inquietudes propias del bien común; siendo operativo, mantiene la vigencia del ordenamiento" (del autor referenciado "Derecho laboral", tomo 1. P 84, citado por Fernández Madrid, Juan C. "Tratado Práctico de derecho del Trabajo", tomo 1, p. 585).

$3 \mathrm{Y}$ es que desde su definición, se caracteriza al vínculo jurídico laboral como una relación conmutativa - pues genera de por sí obligaciones con mutuo carácter de correlatividad- y oneroso, pues en tanto el artículo 115 de la LCT presume a la figura bajo análisis onerosa (ya que con redacción inversa especifica que "el trabajo no se presume gratuito"), la remuneración o el fin económico del trabajador resulta esencial para cualificar a una figura como "contrato de trabajo", aún cuando no se requiera una télesis lucrativa por parte de quien se beneficia directamente con la prestación del obrero. 


\section{3.- Algunas posturas relacionistas. Su faz clásica}

En una primera línea, haremos mención a ciertas ideas que corresponden al sector de autores que entienden que el vínculo laboral se corresponde al campo de la relación jurídica, más que a la noción de contrato.

Podemos decir así que mientras la tradición contractual procede del derecho Romano, confirmándose en Francia con la Revolución Francesa y el Código Napoleón, la doctrina anti contractualista hunde sus raíces en la filosofía y la teología alemanas. En base a esta última posición, se considera que la parte está siempre predeterminada por el todo, o dicho de otro modo, lo primero no es el individuo que suscribe un contrato, sino la relación que se establece entre una persona y una institución, definiéndose al trabajo desde esta perspectiva como la relación mediante la cual el individuo se integra en la comunidad ${ }^{4}$ (Candal, 2011:277).

Dos juristas alemanes, Otto Von Gierke y Heiz Potthoff, destacaban el carácter individualista e insolidario del vínculo jurídico laboral, sirviendo de inspiración posterior para los trabajos de Wolfgang Siebert, quien sostuvo en 1930 que la relación laboral no se fundaba en un acto contractual sino en el hecho de la incorporación del trabajador en la empresa (Eingliederung).

Gierke sostuvo la imposibilidad de concebir jurídicamente al individuo si no se tenía en cuenta la comunidad a la que pertenecía, agregando que ni la voluntad individual ni la del Estado podía ser fuente de derechos, siendo ésta siempre la conciencia común. En este sentido, la relación de trabajo por tanto significaba una relación de pertenencia a una comunidad, relación que nacía en el momento de la integración del individuo a la misma, y no en base a un simple contrato. Aclara finalmente que la pertenencia a la empresa era la verdadera fuente de la relación jurídica del trabajo, la que confería la condición de miembro de esa comunidad.

Como se advierte, la concepción alemana de la empresa y del trabajo se enmarcaron en una filosofía política para la que sociedad y comunidad

\footnotetext{
4 Vale decir que el antiguo Derecho germánico reconocía, junto a la relación servil, un contrato de vasallaje por medio del cual un hombre libre servía a otro a cambio de protección, ayuda y representación. Este contrato creaba un vínculo personal de recíproca lealtad que se asemejaba a los vínculos familiares, y hacía participar a los que quedaban ligados con él, de una misma comunidad de derechos y obligaciones. Esta concepción se opondrá durante el S XIX a la visión individualista del trabajo, propia de la cultura jurídica de raigambre romana.
} 
significaban lo mismo. En este sentido, la empresa era a un tiempo una sociedad política a escala y un elemento de la gran sociedad política (Candal, 2011:278).

En el intento de construir una teoría de la empresa y su base política, dos institucionalistas como León Duguit y Maurice Hauriou, al sostener la preeminencia de la institución sobre los aspectos sociales, formalizaron una crítica sobre la idea que defiende al contrato como base de las relaciones jurídicas laborales.

En esa línea, Gounot expresaba que el contrato de trabajo mismo, que se presentaba como un hecho primario y originario, no dejaba de ser un hecho secundario y derivado, y ampliaba dicha idea diciendo que la propia figura del contrato suponía por sí además de un primer paso hacia la división del trabajo, una organización social compleja y relativamente estable, suficiente como para que los individuos considerasen oportuno prever sobre su futuro. Proseguía diciendo que

junto a los contratos, en lo que los obreros intervienen como partes, está la institución orgánica de la que se convierten en miembros: miembros solidarios, cuya colaboración activa e inteligente en una obra común y cuya sumisión a una misma disciplina hacen de ellos verdaderos asociados (S/R)

Mario de la Cueva afirmó también en este orden de ideas que los efectos de carácter laboral del vínculo que unía a trabajador y un empleador, no se producían por el acuerdo de voluntades, sino a partir del momento en que el trabajador iniciaba la efectiva prestación de servicios, es decir, desde el momento en que el mismo se incorporaba a la empresa ${ }^{5}$.

Paul Durand desde la doctrina francesa también hizo grandes aportes a la teoría institucionalista como base del vínculo jurídico laboral, afirmando que resultaba imposible encorsetar a la relación de trabajo en una noción jurídica unitaria, siendo que la definición misma de esa vinculación debía elaborarse tanto a partir del contrato como de la institución, es decir nutriéndose de ambas tradiciones, la romanista y la germánica.

5 De esa manera, interpretando el artículo 49 de la por entonces Ley Federal Mexicana del Trabajo (que facultaba al sindicato que encuadraba la actividad empresarial, a seleccionar los trabajadores que eran llamados a ocupar la vacante generada), De la Cueva afirmaba que dicha situación impedía hablar de un contrato en los términos del Código Civil, puesto que dentro del mismo resultaba inadmisible la existencia de un contrato que no tuviese por base la libre voluntad de ambas partes (citado por Cabanellas, Guillermo, en su Tratado de Derecho Laboral tomo II, p. 99 y 100). 
Hasta ahora nos encargamos de mostrar simplemente algunos exponentes de las teorías relacionistas, sobre todo ciertas líneas elementales, como la visión de la empresa como comunidad y fuente de los principales derechos y obligaciones emanados del vínculo laboral entre empleador y trabajador.

\section{4.- Críticas formuladas a las tesis relacionistas}

Es interesante ahora analizar ciertas críticas que desde el contractualismo se fueron construyendo para romper con ciertos moldes creados por los institucionalistas clásicos.

De esta manera autores como Vazquez Vialard (1979) se han manifestado diciendo que en rigor de verdad la distinción teórica efectuada era meramente doctrinaria, y que debía prevalecer la tesis del contrato de trabajo, ya que de otra manera se trataría de asimilar la relación de trabajo a un contrato real del Código Civil que solo se perfeccionaba mediante la prestación de tareas (204).

Agregaba el autor de cita que si bien el relacionismo tenía la ventaja de solucionar ciertas situaciones como la nulidad del negocio jurídico contractual por carencia de algún elemento esencial o estar este viciado intrínsecamente, haciendo prevalecer la realidad de los hechos y la efectiva prestación de servicios por el trabajador, lo cierto es que no tenía entidad suficiente como para quitarle fuerza al propio contrato de trabajo.

En la misma senda, Krotoschin (1955) afirmaba que el error en que había incurrido la teoría de la relación de trabajo era que suponía que ésta (caracterizada por la incorporación a la empresa y la prestación del trabajo) tenía una realidad más constante y más eficaz que el contrato de trabajo, siendo que ambas instituciones coincidían, no habiendo motivo para atribuir como efecto a la relación de trabajo y a la incorporación como miembro al ente social que constituía la empresa, lo que además podía atribuirse al contrato de trabajo regulado en parte por normas objetivas de orden público, y en parte por normas subjetivas e individuales (165).

Muy interesante fue la construcción lograda por Marcos Satanowsky quien, desde su Tratado de Derecho Comercial escrito en 1957, elaboró una serie de críticas importantes a teoría de la institución.

En cuanto a esto decía que entre el individuo y el Estado existían grupos sociales cuya actividad exteriorizaba la realidad de su existencia independientemente de sus componentes, y que la unión del todo o su unidad, 
resultaba de la comunión de las partes en la idea de obra o empresa por realizar a partir de un denominado fin social.

Alejándonos un poco de su parte propedéutica, y adentrándonos dentro de la faz negativa que él advertía tener la institución, decía por un lado que en la misma se anteponía al individuo la autoridad allí construida, sin explicar claramente en virtud de qué fundamentos debía surgir esa autoridad ni por qué debía prevalecer, a lo que agregaba -y esto es lo sustancial que queremos destacar aquí-, que hasta el momento de sus investigaciones (nos tenemos que ubicar en el año de publicación de su monumental obra, ocurrida en 1957), la institución solamente había servido de instrumento en los países totalitarios para justificar medidas dictatoriales en desmedro de la libertad individual.

Proseguía diciendo que en crítica a la obra de George Renard -que apuntaba a la defensa de la posición realista de la institución-, advertía que en la misma se justificaba una ruptura del equilibrio entre lo colectivo y lo individual en perjuicio de la libertad ${ }^{6}$.

\section{5.- Algunas ideas contractualistas para delimitar la relación de apropiación laboral}

Luego de las anteriores críticas que fueron sintetizadas en sus aspectos más relevantes, nos adentraremos en algunas consideraciones de las tesis contractualistas.

Con ese norte, podemos marcar dos rumbos: uno histórico y otro más actual, respecto a la configuración del tracto apropiativo laboral en esos rieles. De esa manera, primeramente haremos referencia a ciertos autores clásicos que trataron de explicar la naturaleza de la vinculación entre trabajador y empleador, y en el segundo segmento, sintetizaremos algunos discursos contemporáneos en la materia.

Respetando el plan antes trazado, es importante remarcar que desde un aspecto histórico, se han construido varias líneas expositivas. Por un lado, la que

6 En esto, cita a G. Gurvich, quien ha expresado que: "La tesis realista al proyectar al exterior la totalidad de los miembros, no puede menos que romper el equilibrio entre lo colectivo y lo individual en beneficio del primero de esos elementos; conduce a la subordinación, a la dominación, a una estructura autoritaria en las relaciones entre el todo y sus partes, al predominio de una parte sobre las otras, a la negación de la igualdad, considerada necesariamente como contractualista" (L'idée du droit social, Paris 1932, citado en la obra Tratado de Derecho Comercial de Marcos Satanowsky, t. 1 p. 86). 
acercaba el contrato de trabajo a la figura de la locación, seguida por la que lo aproximaba más a la compraventa, a la sociedad, o al mandato. Advertimos que por razones de brevedad, solamente expondremos pocas palabras de cada una de estas interpretaciones, so pena de perder el hilo conductor que nos ha motivado a incursionar someramente en lo que consideramos la esencia del vínculo jurídico laboral.

Podemos decir así que, desde la tesis que trató de aproximar al denominado contrato de trabajo con la locación, Planiol (en Pozo, 1961:159) argumentó diciendo que el trabajo podía ser objeto de muchos contratos, pero siempre la cosa locada era la fuerza de trabajo que podía ser utilizada por otra parte, como la máquina o un animal. Barassi en la misma línea, asemejaba el contrato de trabajo a la locación de $\operatorname{cosas}^{7}$, tomando en cuenta según advierte en su obra que en Roma se construía tal equiparación en razón de la importancia que tenía por entonces el trabajo de los esclavos; era el instituto de la locatio conductio ${ }^{8}$.

En una línea posterior, Carnelutti trató de aproximar -también desde contractualismo-, el contrato de trabajo con la compraventa, sobre todo a partir de sus estudios de la energía como objeto de las relaciones jurídicas. En esto decía que mientras en la locación debía devolverse la cosa recibida, esto no sucedía cuando de lo que se trataba era de la energía como elemento negociable (la energía de los trabajadores, una de sus propiedades más elementales), es decir el objeto mismo del contrato de trabajo según su interpretación. Él entendía que lo que se negociaba en el vínculo laboral no era el cuerpo de los

7 Afirma en ese sentido que -sin perjuicio de no haber tomado nunca en serio el apareamiento hecho por Troplong de la operae de los esclavos, y de rechazar la equiparación efectuada entre la locación de la energía humana y la utilidad de las cosas materiales-: "el empleo amplio de la palabra locare para aludir a la concesión de goce no sería razón de escándalo (...) desde el momento que el obrero, al dejarse incorporar a una empresa, pone precisamente a disposición del empresario sus energías. Los conceptos cuentan más que las palabras y podría agregar que la disponibilidad concedida al empresario no lesiona la dignidad del obrero" (ver su "Tratado de Derecho del Trabajo", Buenos Aires: Editorial Alfa, nota 181, pagina 350).

8 La locatio conductio sirvió para identificar primero al trabajo prestado por los esclavos, y luego al que cumplían los hombres libres, siendo a su vez sub dividida posteriormente, en las denominadas locatio conductio operis -que tenía por objeto la utilización de la fuerza de trabajo para cualquier resultado-, y la locatio conductio operarum -mediante la cual el trabajador se limitaba a la realización de una obra determinada-. Esta última versión es la que se aproxima al viejo instituto de la locación de obra inserta en el Código de Vélez. 
trabajadores -o el trabajador mismo, que sería la fuente de emanación-, sino solamente su energía -o parte de la misma- ${ }^{9}$.

Aun habiendo logrado un gentil trato doctrinario con Barassi -cuyos aportes calificó de admirables-, Carnelutti lo criticó en parte afirmando que su esfuerzo, más que resucitar la concepción romana (de la locatio), había servido para liquidarla definitivamente, porque a la luz de un análisis profundizado se veía claramente que el objeto de la locación no podía ser más que la cosa, de donde brotaba el trabajo, y no el trabajo en sí ${ }^{10}$.

Desde otra mirada, se trató de asimilar al vínculo jurídico laboral con el de sociedad, expresando aquí Chatelain que en las relaciones entre trabajadores y empleadores existían dos elementos de tal figura, que eran por un lado la obra en común como resultado del aporte de varias personas, y por el otro, la división de los beneficios, aunque a poco de ser construía esa forma de interpretación se dijo correctamente que el empleador es el único dueño de la producción, y que como consecuencia de ello las ganancias no son en ninguna forma repartidas, sino acaparadas por quien manifestaba tener la titularidad de la empresa, siendo fijada en paralelo la denominada ganancia del trabajador -o su remuneración-, sin tomar en cuenta necesariamente el nivel de ingresos del empresario ${ }^{11}$.

Por último, dentro de las clásicas vertientes del contractualismo, citaremos la tesis que trata de identificar al contrato de trabajo con el mandato (más que nada en su versión onerosa), en tanto según algunos entendían, el trabajador recibía y debía respetar las directivas de otra persona en el cumplimiento de sus tareas, a cambio de una cantidad de dinero. Aunque desde otro sector se ha criticado tal asimilación desde el momento en que mientras el mandato es un contrato de representación -realización de actos jurídicos a nombre de otra persona-, el contrato de trabajo contrariamente, tiene por objeto principal una prestación de tareas a favor de otro, entre otras diferencias.

9 Aquí nos preguntamos en qué medida la venta de la energía de los trabajadores no supone también la enajenación de su persona toda, al menos en cierta medida.

10 Ver, Cornaglia "Reforma laboral”, pagina 209.

11 En tal sentido, ha afirmado Juan Carlos Fernández Madrid que si bien la prestación de servicios está dirigida a la obtención de un objetivo que es común entre empleador y trabajador desde el aspecto funcional, tal carácter no identifica a las partes del contrato con una finalidad común, porque en tanto para el empleador el objeto del negocio es la obtención de una utilidad económica, el trabajador resulta ajeno a dichos réditos, siendo su motivación la idea de obtener un medio de subsistencia ("Tratado", 2007:680). 
Alejándonos un poco de las formas clásicas que adoptó el contractualismo, Krotoschin, contrario a la exclusividad de la idea fáctica -que entendía esencial de base para la constitución del vínculo jurídico laboral-, decía que el estatuto de la empresa no era solamente de derecho objetivo, aún cuando reconocía la importancia especial que la norma imperativa adquiría en el derecho del trabajo, frente a la voluntad de las partes individuales la que, subrayaba, no quedaba sin embargo descartada (1955:164), afirmando además que el contrato era previo a la fase de ejecución, persistía desde luego durante la misma, y hasta tenía constancia cuando la ejecución se hubiera suspendido o interrumpido (por ejemplo por enfermedad, accidente, etc). En este último sentido, agregaba que el trabajador no valía pura y simplemente como parte de un todo (empresa), sino que era, como individuo, superior a la misma, manteniendo una posición de derecho netamente perfilada aun independientemente del destino que pudiese correr en determinado momento la prestación (1955:166).

En la misma línea, Guillermo Cabanellas afirmó que "bien por razón de la existencia de lazos personales, o por considerar el contrato dividido en tres estadíos diferentes, la realidad es que el acuerdo de voluntades subsiste; y así conviene que siga ocurriendo", agregando asimismo que la relación laboral se integraba por el acuerdo contractual que le era precedente, y que ambas figuras no constituían dos conceptos diferentes, sino complementarios $(1949: 94)^{12}$.

Fernández Madrid también sigue la tesis contractualista al momento de delimitar conceptualmente el vínculo jurídico laboral, aun cuando destaca que si bien el consentimiento origina tal negocio legal, el mismo no regla lo fundamental de la relación, ya que las condiciones de trabajo vienen predeterminadas en gran medida por el legislador o por la autonomía de las partes colectivas, imponiendo de esa manera condiciones mínimas de labor, que habilita en su caso la posibilidad de pactar libremente sólo por encima de tal piso (2007:674).

Quizá una de las mejores construcciones contemporáneas dentro del contractualismo, sea la elaborada por Ricardo Cornaglia (2001), quien entiende a la enajenación del trabajo (que califica también como conducta laboral, objeto del negocio), como una transferencia de carácter patrimonial y también de poder, más cerca a la figura de la venta que a la de la locación, manifestando al

12 Sin perjuicio de ello, Cabanellas -citando la opinión de Pérez Botija-, transcribe que "naturalmente, el nuevo contrato de trabajo no es el antiguo. Ha cambiado su contenido y fisonomía. Ya no es un simple cambio de prestaciones, sino que va dirigido a la creación de lazos personales, a la incorporación a una comunidad de trabajo” (Tratado de Derecho Laboral, tomo II, página 94). 
respecto que: "puesto que quien se apropió de ella -refiere a la energía del trabajador-, puede que la use y goce, pero lo que es más importante está en condición legal de transmitirla incorporada a los bienes, servicios y mercaderías producidos. En realidad los realiza en ellos y para el trabajador, esto significa la enajenación" (211).

Finalmente, mencionamos la teoría del contrato de trabajo autónomo, cuyos defensores, argumentando que existían dudas respecto a que el vínculo jurídico laboral tuviese puntos de encuentro y semejanzas con otros contratos del derecho civil -entre ellos la locación-, remarcaron un conjunto de diferencias estructurales y de esencia entre ambos campos legales, concluyendo que resultaba imposible aplicarle al vínculo laboral las normas de los contratos del derecho privado clásico.

En ese orden, se ha señalado que si bien en el contrato de trabajo existe un aspecto patrimonial -cumplido por la remuneración del trabajador y la ganancia del empleador-, lo cierto es que prevalece un aspecto personal esencial en su configuración, como lo es la energía laboral del trabajador ${ }^{13}$.

De esa manera, Pérez Botija, en parcial superación a la tesis de los contratos innominados, y luego de expresar que el tracto laboral reunía unas notas generales y particulares que lo situaban perfectamente dentro de una sustantiva y auténtica figura del contrato, afirmó que el nuevo tipo contractual ofrecía un régimen jurídico autónomo y bastante completo, superando su ordenamiento en múltiples aspectos, al de algunos contratos clásicos (Deveali, 1953:182).

De todos modos, se afirma que el contrato de trabajo es una figura especial o autónoma, con ciertas particularidades, como por ejemplo la imperatividad del tipo legal como vimos en la riera parte del presente artículo (en lo que también actúa la presunción de existencia del contrato, receptado en nuestro derecho positivo en el artículo 23 de la LCT), operando la limitación de la voluntad de las partes en base sobre todo a la incidencia del orden público laboral, en función del cual los contratantes no pueden reducir las condiciones de trabajo fijadas por la ley o las convenciones colectivas de trabajo, a la par que se

13 Aquí, advertimos que Juan D. Pozzo en su Manual Teórico Práctico de Derecho el Trabajo, nos da a entender que para él la fuerza de trabajo no le pertenece al trabajador, sino al propio contrato de trabajo, que vendría a cumplir las veces de una entidad independiente de las partes, según parece desprenderse de esa concepción. Así, afirma que "si bien existe en el contrato de trabajo un contenido patrimonial, también existe el elemento personal, ya que como lo señala Lotmer, el objeto de la prestación, o sea la fuerza de trabajo, no es algo que pertenece al patrimonio del trabajador" (Manual.., tomo 1, p. 162). 
reconoce también la subordinación de la voluntad del trabajador frente a la del empleador que, aunque puede tener tres variantes -técnica, económica y jurídica-, siempre da prevalencia a ésta última forma por ser considerada condimento exacto para la relación laboral ${ }^{14}$.

\section{6.- Posturas intermedias}

Para conciliar -en parte- las tesis relacionistas con las contractualistas, Justo López trató de construir una tesis intermedia a partir de la cual poder ensamblar ciertos contenidos provenientes de la discusión anterior.

En primer lugar afirmó que el contrato de trabajo era el negocio jurídico más significativo en la materia por ser la figura normalmente constitutiva de la relación laboral, y que esa afirmación por sí misma oponía el contrato a la propia relación por él constituída.

En una segunda y complementaria mirada, dicho autor refirió que también había que distinguir el contrato como acto negocial (bilateral) que era, en expresión de Santi Romano, un acto jurídico normativo no autoritario (distinguiéndose de la ley, la sentencia o la resolución administrativa, que serían actos jurídicos normativos autoritarios, por tener su causa fuente en la autoridad desempeñada por el Estado), y lo que Betti (1977) llamaba contenido de ese acto negocial: un precepto de autonomía privada; y que mediante ese acto normativo no autoritario bilateral que era el contrato, partes con intereses opuestos ponían preceptos jurídicos que eran cláusulas constitutivas del contrato (176).

En este sentido, refería que había que distinguir por un lado el acto negocial (normativo), las normas jurídicas (cláusulas contractuales) creadas por ese acto (que sería un acuerdo respecto de su creación), y la relación jurídica (relación obligatoria, complejo de posiciones jurídicas favorables y desfavorables), constituida y regulada por esas normas (176).

De esta manera Justo López, desde el punto de vista jurídico, trató de fijar una posición que creemos intermedia entre aquellos que intentaban estudiar las vinculaciones posibles entre el contrato y relación de trabajo receptadas en los

14 La dependencia jurídica se traduce en la posibilidad que tiene el empleador de sustituir la voluntad del trabajador por la suya propia, o, como expresa Fernández Madrid, en la "facultad de ordenar y de adecuar las prestaciones concretas del trabajador a los fines de la empresa y por la obligación de éste de aceptar el ejercicio de dicha facultad" (Tratado, tomo 1, p. 687). 
artículos 21 y 22 de la LCT, aunque lo cierto es que en parte se alejó de la esencia de la discusión entre relacionistas y contractualistas, en ocasión de terminar la naturaleza del vínculo que une un trabajador con su empleador.

Por otra parte, y desde el derecho europeo, Alain Supiot (1996) también ha construido una serie de variantes a tener en cuenta.

En efecto, ese autor manifiesta que, desde un punto de vista doctrinal, la controversia entre las culturas románicas y germánicas parece cerrada en un sentido favorable a la tesis contractual, afirmando además que la cuestión parecería resuelta en su beneficio de reducirse el problema de la fuente de la fuerza obligatoria de la relación laboral, considerándose que gran parte de los autores entienden necesario un acuerdo inicial para la formación regular de una relación de trabajo subordinada (44).

Pero agrega el autor de cita que tampoco cabía perder de vista que el mantenimiento del análisis contractual sólo había sido posible pagando el precio de una mutación compleja de la vieja noción de arrendamiento de servicios, y que el análisis contractual de la relación de trabajo no habría podido sobrevivir en los diferentes sistemas jurídicos europeos, sino incorporando ciertos aspectos de la concepción germánica y también reconociendo la dimensión personal del compromiso del trabajador (44).

De esa manera, critica la formulación actual del contrato de trabajo, advirtiendo que se trataría de una "forma jurídica obesa", sobrecargada de derechos provenientes de la ley, los convenios colectivos, la jurisprudencia, entre otras fuentes, y advierte que en los países latinos se ha llevado a cabo una absorción por el contrato de los valores personales inherentes a la relación de trabajo. En esto último, especifica que en parte el Derecho del Trabajo está dominado por el rol eminente conferido a los poderes públicos en la reglamentación de la relación laboral, en la medida en que se ha creado en ciertos países como Francia la noción de orden público social (u orden público laboral, como se reproduce en la doctrina nacional) que implica, por un lado otorgar cierta jerarquía a las normas vinculadas con la materia y, por el otro, brindar un trato preferencial a los trabajadores, excluyendo cualquier derogación contractual in pejus de las reglas legales y de las disposiciones de los convenios colectivos de trabajo.

Finaliza esta idea diciendo que en todos los países de la Europa comunitaria, el contrato ha servido de marco a la definición jurídica de la relación de trabajo, pero que el mantenimiento de tal marco no habría sido posible sino mediante 
la absorción por parte del contrato, de un estatuto del trabajador asalariado, definiendo estatuto como el estado de la persona del trabajador que implica el conjunto de derechos y deberes definido con independencia de su voluntad (por ley, por convenio colectivo, entre otras fuentes), y que lleva a la presunción sociológica de la existencia de una comunidad en que dicho estado adquiriría sentido.

\section{7.- Nuestra posición: la relación de trabajo como relación de poder}

En los párrafos y líneas anteriores tratamos de exponer los lineamientos generales de las dos posturas que existen actualmente en el campo del derecho social, y que son citadas a la hora de determinar la naturaleza o esencia del vínculo individual laboral, apuntando nosotros no tanto a un análisis legal (aunque necesariamente se hizo mención a una serie de normativas nacionales), sino que más bien la idea fue tratar de aprehender ónticamente el denominado contrato de trabajo.

Asimismo, en ese afán propuesto, también seleccionamos algunas ideas que no se enrolan puramente en ninguna de las dos tesis clásicas, sino que tratan de estudiar ciertos matices que se dan al momento de delimitar doctrinariamente, el alcance y el sentido de la relación que vincula a un trabajador con un empleador.

Con todo lo anterior, creímos oportuno en este punto brindar una opinión personal sobre el ítem en desarrollo. Así, entendemos que el vínculo jurídico laboral en que se entrelazan actualmente los intereses del trabajador con los del empleador, no puede cualificarse como contrato de trabajo sino como relación laboral, sin desmerecer por ello los argumentos provenientes de la postura contrapuesta, defendida en muchos casos por eminentes exponentes.

Reiteramos que al discutir la naturaleza del vínculo socio laboral, tratamos de alejarnos un poco de la ley positiva (que en definitiva prioriza la denominación de contrato, como ocurre con la Ley 20.744 "De contrato de trabajo"), para adentrarnos en una discusión en parte sociológica del instituto analizado.

Sobre lo anterior, creemos que de ninguna forma podemos comprender la esencia de la vinculación laboral defendiendo la idea de un contrato que a nuestro modo de ver no existe, y que las contradicciones provenientes de la tesis contractual no se salvan siquiera con el reconocimiento del carácter ambivalente de Derecho del Trabajo, que tuvimos la oportunidad de desarrollar en otro trabajo (Balbin, 2015: S/P). 
Algunos autores como Adrián Goldín han expresado que en el vinculo social, conviven la libertad y el sometimiento, y que aunque la idea del contrato implicaba por un lado "el luminoso reconocimiento del trabajador como persona libre, habilitada para decidir sobre la puesta a disposición de su capacidad de trabajo", por el otro habilitaba para corroborar la existencia misma de condiciones de sometimiento" (2014).

Lo que verdaderamente existe entre trabajador y empleador, a nuestro entender, es una relación jurídica basada en un poder permanente que detenta el empleador, y que proyecta sus efectos a lo largo de toda la vida del vínculo entre el trabajador y el empleador. Existe en manos del empleador un micro poder que ejerce permanentemente violencia sobre la persona del trabajador, ya sea con la directa aplicación de alguna sanción, o bien con la mera amenaza de hacerlo, es decir, cuando la violencia permanece latente a sabiendas del propio trabajador y justificada por un sistema legal que en parte lo habilita. Luego, si hablamos de "sometimiento" como lo hace Goldín según antes citamos, nos queda desfasada la idea misma de contrato como figura encuadrante del tracto apropiativo laboral, que campea por sí misma en las arenas de la libertad e igualdad.

Al respecto Mario Ackerman (2007) -aún defendiendo la idea de la existencia de un contrato de trabajo-, sostuvo en un artículo que la relación de dependencia laboral, escapa notoriamente de la clásica idea acreedor-deudor propia del derecho de las obligaciones, y que el trabajador es un sujeto mediatizado, pues al vincularse económicamente con un empresario, deja de cumplir una función para sí o la colectividad, y pasa a ser un sujeto de lo ajeno, en beneficio exclusivamente de ello.

Entendemos pues que sólo una deformación de la idea misma de contrato nos puede conducir a la adopción de tal figura proveniente del derecho común en el Derecho del Trabajo, y son tantos los condimentos especiales con que se trata de matizar a esa institución en la materia (contrato sometimiento, contrato intervenido, contrato autónomo o especial, entre muchas otras), que difícilmente detrás de todo ese ropaje nos quede alguna idea útil e hidratada para utilizar con eficacia ni más ni menos que como forma de encuadrar dos voluntades contrapuestas y con intereses dispares.

Se critica a la tesis relacionista que en parte tenga su origen en el institucionalismo alemán e intente -como se vio anteriormente-, sobreponer la idea de la empresa-comunidad y su autoridad central en cabeza del empleador o jefe, a la propia del trabajador, lo que también para cierto sector de la doctrina 
(ver apartado destinado a referenciar la postura de Marcos Satanosky), sirvió para justificar en ocasiones regímenes totalitarios, como el fascismo italiano y con él la Carta del Lavoro ${ }^{15}$.

Sin desmerecer las opiniones de los autores que señalan ese punto, estamos contestes con otra mirada del relacionismo, una mirada mucho más moderna que entiende que el desnivel de poderes ínsito en la relación de trabajo, nunca podría conducir a calificar de contrato al vínculo apropiativo que le sirve de sustento.

Al respecto, y con agudeza, ha señalado el maestro Ángel Gatti (2015) que

la diversidad de criterios no está totalmente disipada -aunque cierta prestigiosa doctrina la dé por superada a favor de la teoría contractualista-; en rigor, no parece suficiente la afirmación dogmática, aunque se exprese con vehemencia y sincera convicción, en un tema de enorme complejidad, dadas sus implicancias, y rico en posibilidades argumentativas. (Gatti:110)

Adunado a lo anterior, creemos que si se critica al relacionismo por tener ramificaciones en el sistema totalitario de la Europa occidental del siglo XX, bien podríamos criticar al contractualismo por tener sus orígenes en las tesis civilistas como las de Carnelutti, Barassi, Chatelain, entre otros autores clásicos, que trataron de asemejar el tracto apropiativo laboral con la compraventa, la locación de servicios o el mandato, no advirtiendo seriamente -ni siquiera a inicios de siglo XX, época en la cual algunas de esas tesis se desarrollaron-, que el núcleo de la relación laboral se centra no en la libertad e igualdad de ambos contratantes, sino en una desigual distribución de poderes en beneficio del empleador, en un vínculo cualificado por un sometimiento casi permanente del trabajador, y un egoísmo y ceguera repetidas de parte del ala políticogobernante, en otras palabras, en un poder de control en manos del dueño de la empresa y justificado por el propio sistema.

15 Recordemos que este instrumento actualmente vetusto, decía en su letra que "La nación italiana es una organización que tiene finalidades, vida y medios de acción superiores en potencia y duración a los poseídos por los individuos o grupos que la integran”. R. Hubert, comentando esa normativa, dijo que una de las características del fascismo italiano era su voluntad de integrar todos los cuerpos sociales en la organización del Estado y por consiguiente subordinarlos integralmente a sus fines supremos, a lo que agrega que esta era una concepción hegeliana del Estado como ideafuerza, y que no correspondía a las verdaderas necesidades de la sociedad moderna (ver nota 221 del capítulo IX del Tratado de Derecho Comercial de Marcos Satanosky, tomo 1,año 1957). 
Creemos que si ponemos todas las cartas sobre la mesa bien podemos llegar a mejores conclusiones, y reiteramos nuestra adhesión a la tesis relacionista en su versión moderna por los fundamentos que antes hemos expuesto.

\section{8.- Conclusiones}

El vínculo jurídico de trabajo es sin duda, una de las figuras con mayor extensión en nuestros días, y para comprenderlo, es una herramienta útil discutir sobre su esencia legal y real, subrayando ciertos efectos que produce su aplicación práctica, aún no sujetándonos a un análisis puramente positivo, como intentamos efectuar en este artículo.

El vínculo laboral es una típica relación legal, mas no un contrato en sentido estricto, conclusión a la que arribamos luego de tratar ciertos puntos trabajados por destacados autores, y de tomar partido al respecto, enlazando esas ideas con el carácter ambivalente del derecho del trabajo.

El hecho de que la ley 20.744 se titule De Contrato de Trabajo, no es óbice para la defensa de una tesis contraria a su respecto, idea que no se desnaturaliza ni mucho menos, con la clásica distinción de los artículos 21 -contrato- y 22 relación de trabajo-, tratados en dicho cuerpo legal, pues nuestro norte aquí fue alejarnos en parte del texto de legal, adentrándonos en discusiones más abstractas, aunque no por ello solamente académicas, proyectando desde la teoría de la relación de trabajo, cierta luz a la praxis socio laboral, a partir de la cual bien podemos entender el desarrollo y la existencia de algunos institutos claramente desiguales dentro de una materia llamada a tutelar un interés económicamente retraído.

La relación de trabajo es, por ende, un vínculo de poder desigual, en beneficio del empleador. Cierto es que los trabajadores también son titulares de poderes (como los derivados de la actuación sindical, o de la norma colectiva), mas en lo cotidiano, la balanza sigue beneficiando a los titulares de los medios materiales de producción.

Ese poder se reproduce de manera permanente, y en parte es avalado por el propio sistema político, ejerciendo en ocasiones ciertas formas de violencia de carácter multifacética sobre la persona del trabajador.

Ahondar en la discusión sobre la naturaleza del vínculo jurídico de trabajo no es, ni cerca, una tarea inútil, así como tampoco resulta arcaico defender la tesis de la relación laboral. Antes bien, colabora para aportar más claridad sobre un nexo económico personal, en permanente conflicto. 


\section{9.- Bibliografía}

ACKerman, M. (2008). "El trabajo, los trabajadores y el Derecho del Trabajo". Publicado en Revista de Trabajo, año 3, nro. 4, mes de Enero.

Balbín, A. N. (2015). "El concepto de Derecho del Trabajo", publicado en Revista Anales de la Facultad de Ciencias Jurídicas y Sociales, Universidad Nacional de La Plata, año 12 nro. 45.

BARAssi, L. (1953). Tratado de Derecho del Trabajo, Buenos Aires: Editorial Alfa.

Cabanellas, G. (1949). Tratado de Derecho laboral, tomo II. Buenos aires: Editorial Bibliográfica Argentina.

CANDAL, P. (2011). "Del contrato de trabajo en general". Capítulo publicado en la obra mayor "Ley de contrato de trabajo. Comentada y concordada" T. 1. Segunda edición actualizada, de Ojeda, Raúl Horacio (coordinador), Buenos Aires: Rubinzal Culzoni.

Cornaglia, R. J. (2001). Reforma Laboral, Análisis Crítico. Aportes para una Teoría General del Derecho del Trabajo en la Crisis. Buenos Aires: La Ley.

Deveali, Mario. (1953). Lineamientos del Derecho del Trabajo, Buenos Aires: Edit. Tipográfica Editoria Argentina.

Etala, C. A. (2011). Contrato de trabajo, comentada y anotada. Buenos Aires: Astrea.

FernándeZ, J. C.(2007).Tratado Práctico de Derecho del Trabajo, Tomos I y II. Buenos Aires: La Ley.

GatTI, A. E. (2015). Derecho del Trabajo. Manual de las relaciones individuales. Buenos Aires: Ediciones B de F.

Goldín, A. (2014). "Algunos rasgos definitorios de un Derecho del Trabajo en proceso de cambio". THĒMIS- Revista de Derecho [artículo on line disponible en:revistas.pucp.edu.pe/index.php/themis/article/download/10847/11353].

Krotoschin, E. (1955). Tratado de Derecho del Trabajo. Buenos Aires: Depalma.

López, J. Centeno, N. y Fernández, J. C. (1987). Ley de Contrato de Trabajo Comentada, Tomos 1 y 2. Buenos Aires: Ed. Contabilidad Moderna.

Pozzo, J, D. (1961), Manual teórico práctico de Derecho del Trabajo. Buenos Aires: Ediar. 
Satanowsky, Marcos. (1957). Tratado de Derecho Comercial, Tomo 1. Buenos Aires: Tipográfica editora argentina SA.

Supiot, A. (1996). Crítica del Derecho del Trabajo. Madrid: Ministerio de Trabajo y Asuntos Sociales.

VazQuez Vialard, A. (1979). Derecho de Trabajo y de la Seguridad Social. Buenos Aires: Depalma.

(1982). Tratado de Derecho del Trabajo, tomo 3. Buenos Aires: Editorial Astrea. 